\title{
Research article \\ Effect of vitamin D supplementation on fetal growth and development in pregnant women
}

\author{
V. Srilekha ${ }^{1}$, B. Vijayalakshmi ${ }^{2}$, I. Yogananda Reddy ${ }^{3}$, Nayiema Fathima ${ }^{4}$ \\ ${ }^{1}$ Assistant Professor, Department of Physiology, SVS Medical College, Mahabubnagar, 509001 Telangana, India \\ ${ }^{2}$ Professor and Head, Department of Physiology, Saveetha Medical College, Saveetha University, Chennai, Tamil Nadu, India \\ ${ }^{3}$ Professor, Department of Physiology, ESI Medical College, Sanathnagar, Hyderabad, Telangana, India \\ ${ }^{4}$ Professor and Head, Department of Gynecology, SVS Medical College, Mahabubnagar, Telangana, India
}

(Received: August $2021 \quad$ Revised: December $2021 \quad$ Accepted: December 2021)

Corresponding author: V. Srilekha. Email: sreelekha5971@gmail.com

\begin{abstract}
Introduction and Aim: Fetal growth is a dynamic process that must be monitored in pregnant women to reduce the long-term consequences of fetal anomalies and post-natal effects on their life. The current study was aimed to find out the effectiveness and association of vitamin D on fetal growth during the prenatal period.
\end{abstract}

Materials and Methods: It was a randomized control trial undertaken in 100 pregnant women who were allocated randomly into two groups based on calcemic state. After giving 6000 IU of vitamin D intervention the fetal growth was measured at the end of 3 months and the variables were obtained before and after the intervention.

Results: The mean difference of fetal weight between groups was $77 \mathrm{~g}$ was significantly increased to $277 \mathrm{~g}(\mathrm{p}<0.01)$ after 3 months. The mean difference of femur length before intervention was $0.95 \mathrm{~mm}(p-0.18)$ significantly increased to $3.03 \mathrm{~mm}(\mathrm{p}<0.01)$. Further, the mean biparietal diameter difference was $0.13 \mathrm{~mm}(\mathrm{p}-0.92)$ was substantially increased to $4.77 \mathrm{~mm}(\mathrm{p}<0.01)$.

Conclusion: The current study suggests that the fetal growth variables were significantly increased in postintervention phases which can be attributed to vitamin D. It has an immense effect on fetal growth which can be supplemented during different trimesters to enhance fetal development.

Keywords: Fetal growth; bicephalic diameter; cholecalciferol; hypocalcemia; fetal growth restriction.

\section{INTRODUCTION}

$\mathrm{F}$ etal growth is a dynamic process to be measured and monitored intermittently to define physiological evolution and if any abnormal deformities may lead to congenital anomalies (1). Fetal growth is influenced by various factors including genetic, humoral, environmental, nutritional, uteroplacental, and fetal factors that either delay or accelerates the rate of development (2-4). Various clinical conditions are associated with fetal growth restriction especially preeclampsia and preterm birth (5-7). Therefore, the perinatal rate o morbidity and mortality associated with fetal growth restriction can be reduced by constant monitoring of fetal growth every 3-4 weeks $(8,9)$. Appropriate pharmacological measures must be taken to enhance fetal growth which is essential for non-congenital anomalies. There are a wide variety of elements have been used in clinical practice (10-12). The current evidence has been revealed that umbilical blood flow, transplacental insulin, thyroid hormones, and numerous growth factors play a key role in fetal growth (13). Apart from these traditional known factors, vitamin D also advances organ development in the fetal stage (14). Vitamin D is a fat-soluble vitamin that has a classic function to maintain calcium homeostasis and bone strength. Vitamin D is a prohormone synthesized from cholesterol in the skin and hydroxylated in two positions ( 1 and $25^{\text {th }} \mathrm{OH} \mathrm{D}$ ) in the liver and kidney respectivelyto become active calcitriol. Vitamin D stimulates intestinal calcium absorption and is important in maintaining adequate phosphate levels for bone mineralization, bone growth, and remodeling. It's also believed to be involved in the regulation of cell growth proliferation and apoptosis (programmed cell death), as well as modulation of the immune system and other functions $(15,16)$. Across the world, low maternal vitamin D level is common during pregnancy. Maternal low vitamin D levels immensely influence intrauterine development and lead to longterm health complications (17). There is no fetal production of vitamin $\mathrm{D}$, and it completely depends upon maternal transport to enhance fetal growth and development. Low vitamin $D$ has been associated with preeclampsia, preterm birth, small gestational age (SGA; 18). The association between vitamin D supplementation and increase fetal birth weight and reduced SGA was not elucidated. However, there is a shred of evidence that vitamin D supplementation during pregnancy can immensely influence fetal weight and growth (14). There is paucity in the literature which could not explain the illustrated relationship between vitamin D deficiency and reduced fetal growth during pregnancy. Therefore, the current study was intended to find out the impact of standard, allowable vitamin D supplementation on different variables of fetal growth during pregnancy. 


\section{MATERIALS AND METHODS}

A Randomized controlled trial was carried out on 100 pregnant women aged between 20-35 yearsbetween 2019 and 2020. The study protocol was reviewed and approved by the Institutional Ethics committee of SVS Medical College and Hospital, and an approval number (IEC approval No. 02/2019) was obtained before starting the study. The participants were randomly selected who got pregnancy and gestation age between $1^{\text {st }}$ trimester to $3^{\text {rd }}$ trimester were recruited and allocated into study group (50) and control group (50) based on serum calcium levels. Pregnant women with endocrine disorders, hypertensives, a recent history of major surgeries, and trauma, were excluded from the study. The study protocol's benefits were explained to all participants and clarified their willingness to withdraw from the study. A written informed consent document was obtained from all participants as well as from their guardians and adopted the recommendations of the Declaration of Helsinki guidelines (1975) and later amendments.

All study group participants were interviewed about their pregnancy profile. As they have hypocalcemia,6000 IU of vitamin D3 was intravenously infused for three months. The dosage was adopted the recommendations and policies of vitamin D supplementation (20). No adverse effects were reported during the interventional period. Trained nurses carried out all the interventional procedures under the supervision of the fraternity from the gynecology department. The effectiveness of Vitamin D supplementation on fetal growth was measured after three months. The associations of maternal $25(\mathrm{OH}) \mathrm{D}$ concentrations during pregnancy on fetal growth were measured the variables include Bicephalic diameter, femur length, and fetal weight by ultrasonography. Later vitamin D levels were also measured using the CLIA method. These analyses enable optimal use of available data, considering correlations within-subjects and assessing both timedependent and independent associations.

\section{Statistical analysis}

The data sets were analyzed using $\mathrm{R}$ software and represented as Mean \pm SD values. The normality of data was tested using the Smirnov-Kolmogorov test. As the data sets were skewed, all non-parametric tests were implemented to compare the differences in fetal growth between the two groups. The interclass correlation coefficient was performed to find out the association between desired parameters.

\section{RESULTS}

Table 1: The demographic variables of pregnant women in both groups

\begin{tabular}{|c|c|c|c|}
\hline Demographic variables & Study group & Control group & $p$ - value \\
\hline Age (Year) & $27.6 \pm 3.25$ & $27.4 \pm 3.10$ & 0.73 \\
\hline Height (cm) & $159 \pm 5.8$ & $157 \pm 9.5$ & 0.19 \\
\hline Weight (Kg) & $74.9 \pm 14.4$ & $66.5 \pm 12.38$ & $0.02 *$ \\
\hline BMI(Kg/m $\left.{ }^{2}\right)$ & $29.44 \pm 5.83$ & $27.38 \pm 6.38$ & 0.08 \\
\hline Serum Calcium (mg/dl) & $8.13 \pm 0.27$ & $9.49 \pm 0.19$ & $<0.01^{*}$ \\
\hline $\begin{array}{c}\text { Estimated age (Weeks) } \\
\text { Before intervention }\end{array}$ & $16 \pm 4.96$ & $14 \pm 4.30$ & 0.13 \\
\hline $\begin{array}{c}\text { Estimated age (weeks) After } \\
\text { intervention }\end{array}$ & $28.7 \pm 3.72$ & $27.5 \pm 3.54$ & 0.07 \\
\hline $\begin{array}{c}\text { Vitamin D (ng/ml) Before } \\
\text { intervention }\end{array}$ & $21.42 \pm 5.06$ & $21.14 \pm 5.17$ & 0.74 \\
\hline $\begin{array}{c}\text { Vitamin D (ng/ml) } \\
\text { After intervention }\end{array}$ & $33.63 \pm 6.74$ & $24.21 \pm 5.28$ & $<0.01^{*}$ \\
\hline
\end{tabular}

Table 2: The difference in fetal weight before and after intervention

\begin{tabular}{|c|c|c|c|c|c|c|c|}
\hline \multirow{3}{*}{ Assessment } & \multirow{3}{*}{$\mathrm{n}$} & \multicolumn{4}{|c|}{ Group } & \multirow{3}{*}{$\begin{array}{c}\text { Mean } \\
\text { Difference }\end{array}$} & \multirow{3}{*}{$p$-value } \\
\hline & & \multicolumn{2}{|l|}{ Study group } & \multicolumn{2}{|l|}{ Control group } & & \\
\hline & & Mean fetal weight & SD & Mean fetal weight & SD & & \\
\hline $\begin{array}{c}\text { Pre } \\
\text { intervention }\end{array}$ & 50 & 1290 & 329 & 1217 & 189 & 73 & 0.06 \\
\hline $\begin{array}{c}\text { Post } \\
\text { intervention }\end{array}$ & 50 & 1740 & 346 & 1463 & 210 & 277 & $<0.001 *$ \\
\hline
\end{tabular}

Table 3: The difference in femur length before and after intervention

\begin{tabular}{|c|c|c|c|c|c|c|c|}
\hline \multirow{2}{*}{ Assessment } & \multirow{2}{*}{$\mathrm{n}$} & \multicolumn{4}{|c|}{ Group } & \multirow{2}{*}{$\begin{array}{c}\text { Mean } \\
\text { Difference }\end{array}$} & \multirow{2}{*}{$p$-value } \\
\cline { 3 - 6 } & & \multicolumn{2}{|c|}{ Study group } & \multicolumn{2}{c|}{ Control group } & \\
\cline { 3 - 6 } & Mean Femur length & SD & Mean Femur length & SD & & 0.95 & 0.18 \\
\hline Pre intervention & 50 & 32.1 & 3.85 & 33.05 & 3.56 & 3.05 & $<0.01^{*}$ \\
\hline $\begin{array}{c}\text { Post } \\
\text { intervention }\end{array}$ & 50 & 42.04 & 4.99 & 39.03 & 3.91 & 3.03 & \\
\hline
\end{tabular}


Table 4: The difference in biparietal diameter before and after intervention

\begin{tabular}{|c|c|c|c|c|c|c|c|}
\hline \multirow{2}{*}{ Assessment } & \multirow{2}{*}{$\mathrm{n}$} & \multicolumn{4}{|c|}{ Study group } & \multirow{2}{*}{ Mean Difference } & \multirow{2}{*}{$p$-value } \\
\cline { 3 - 8 } & & $\begin{array}{c}\text { Mean Biparietal } \\
\text { diameter }\end{array}$ & SD & $\begin{array}{c}\text { Mean Biparietal } \\
\text { diameter }\end{array}$ & SD & \\
\hline Pre intervention & 50 & 45.40 & 7.85 & 45.53 & 5.06 & 0.13 & 0.92 \\
\hline Post intervention & 50 & 60.30 & 8.54 & 55.53 & 4.52 & 4.77 & $<0.01 *$ \\
\hline
\end{tabular}

* - significant $p$ value

The present study was carried out in 100 pregnant women which were allocated into two groups based on the serum calcemic state. The mean age of the intervention group was $27.6 \pm 3.25$, and the control group was $27.4 \pm 3.10$. All the demographic variables were collected before intervention. Vitamin D levels estimated in both groupswere21.42 $\pm 5.06,21.14 \pm 5.17$ which was not significant before intervention $(p-0.74)$. After 6000IU of vitamin D intervention and a followup of 3 months were significantly increased in the intervention group $(33.63 \pm 6.74)$ than the control group $(24.21 \pm 5.28)\left(p<0.01^{*}\right)$ as displayed in table 1 .

The fetal growth was estimated by ultrasonography and three standard variables were taken to represent fetal growth among all pregnant women. Table 2 shows the mean difference of fetal weight between groups was $77 \mathrm{~g}$ which was significantly increased to $277 \mathrm{~g}(\mathrm{p}<0.01 *)$ after 3 months. The primary criteria for fetal growth were femur length and the mean difference between groups before intervention was $0.95 \mathrm{~mm}(p-0.18)$ significantly increased to $3.03 \mathrm{~mm}$ $\left(\mathrm{p}<0.001^{*}\right)$ as shown in table 3 . Further, the fetal growth was also measured using the biparietal diameter, and the mean difference was $0.13 \mathrm{~mm}$ (p$0.92)$ which was substantially increased to $4.77 \mathrm{~mm}(\mathrm{p}<0.01 *)$ as displayed in table 4 .

\section{DISCUSSION}

The current study was aimed to unveil the association between vitamin D supplementation and fetal growth and development. The results were reported in the study were the rate of fetal growth measured using appropriate variables like fetal weight, femur length, and biparietal diameter in pregnant women with vitamin D intervention was significantly higher than the pregnant women in the control group. The exact physiological pathway of vitamins on fetal growth was not fully understood. However, the postulated mechanisms from the literature have been proposed that the active vitamin $\mathrm{D}$ induces cell proliferation and genomic enhancement which in turn produce the growth factors that effectively promote fetal growth (20). However, the recommendations of WHO are contrary to denotes based on a Cochrane review despite its latest published data $(21,23)$. Furthermore, Barker's hypothesis on immunomodulatory actions of vitamin $\mathrm{D}$ and is evidenced by the diseases in adult life that might be caused due to nutritional insults in perinatal life (24). The vitamin D synthesis in pregnant women is completely dissimilar to non- pregnant women. Vitamin D levels are progressively increased in $1^{\text {st }}$ trimester and attain a peak level of threefold which would cause severe hypercalcemia in a non-pregnant woman (24). But the same vitamin D level during pregnancy is essential to modulate inflammatory reactions and cellular proliferation of healthy fetal tissues. Vitamin D also controls endothelial activity which in turn maintains vascular integrity. This is evidenced by lower vitamin D levels are associated with cardiovascular comorbidities (25). Skeletal growth of fetus mainly depends on calcium deposition, and synthesis of the matrix which is also promoted by the direct effect of activated vitamin D. Maximum fortificationof pregnancy consequences, including preeclampsia in the mother and asthma can be reduced by the supplementation of vitamin $\mathrm{D}$ at least 4000IU (26). The mechanisms remain mysterious, but it is to be expected that epigenetic in utero changes elicited by vitamin $\mathrm{D}$ administered to the pregnant women instructefficient changes in the fetus. It ensures these supplements are safe from the studies carried out in the last two decades, and not even a singleargumentative event has been observed. Further, supplementation lies within the safe intake level as defined by The Endocrine Society.However, the role of vitamin D supplementation in nonclassical, immune linesremains to be encounterand substantiate by recommendations and public health policies for pregnant women (27). Our study has shown that 6000 IU of intravenous vitamin D supplementation has considerably improved the fetal variables to indicate growth is promoted partly by vitamin $\mathrm{D}$. The results of the current study were shown the same trend with literature that can be recommended to the pregnant women.

\section{Limitations}

There are certain limitations to the current study. The sample was less to make a generalized conclusive statement, and we had taken only a few parameters to represent fetal growth. We could measure fetal growth only at once after intervention which could be one of the limitations of our study. Further studies are warranted to make fruitful results using the same methodology with more sample size by conducting longitudinal cohort studies.

\section{CONCLUSION}

The present study outcome reveals that pregnant women after supplementation of vitamin D can effectively improve fetal growth in all dimensions. 
Therefore, vitamin D has a growth-promoting effect, especially in prenatal life. This can be implemented in rural areas where they do not have proper facilities to take care of intrauterine growth.

\section{ACKNOWLEDGEMENT}

The authors express their immense gratitude towards all participants and their great contribution to yield the study outcome and management of SVS Medical College and Hospital for providing basic research facilities and constant encouragement during the study period.

\section{CONFLICT OF INTEREST}

The corresponding author declares on behalf of all authors that there is no potential conflict of interest for the publication of this article.

\section{REFERENCES}

1. Fall, C. H., Yajnik, C. S., Rao, S., Davies, A. A., Brown, N., Farrant, H. J. Micronutrients and fetal growth. The Journal of nutrition. 2003 May 1; 133(5):1747S-1756S.

2. Vorherr, H. Factors influencing fetal growth. American journal of obstetrics and gynecology. 1982 Mar 1; 142(5): 577-588.

3. Mongelli, M. Factors influencing fetal growth. Annals of the Academy of Medicine, Singapore. 2003 May 1; 32(3): 283288.

4. Moh, W., Graham, J. M., Wadhawan, I., Sanchez-Lara, P. A. Extrinsic factors influencing fetal deformations and intrauterine growth restriction. Journal of pregnancy. 2012 Oct; 2012.

5. Bernstein, P. S., Divon, M. Y. Etiologies of fetal growth restriction. Clinical obstetrics and gynecology. 1997 Dec 1; 40(4): 723-729.

6. Odegard, R. A., Vatten, L. J., Nilsen, S. T., Salvesen, K. A., Austgulen, R. Preeclampsia and fetal growth. Obstetrics \& Gynecology. 2000 Dec 1;96(6):950-955.

7. Bakhireva, L. N., Jones, K. L., Schatz, M., Johnson, D., Chambers, C. D. Organization of teratology information services research group. Asthma medication use in pregnancy and fetal growth. Journal of Allergy and Clinical Immunology. 2005 Sep 1; 116(3): 503-509.

8. Gardosi, J. Customised assessment of fetal growth potential: implications for perinatal care. Archives of Disease in Childhood-Fetal and Neonatal Edition. 2012 Sep 1; 97(5): F314-317.

9. Verburg, B. O., Steegers, E.A.P., De Ridder, M., Snijders, R.J.M., Smith, E., Hofman, A., et al., New charts for ultrasound dating of pregnancy and assessment of fetal growth: longitudinal data from a population-based cohort study. Ultrasound in Obstetrics and Gynecology: The Official Journal of the International Society of Ultrasound in Obstetrics and Gynecology. 2008; 31(4): 388-396.

10. Groom, K. M., David, A. L. The role of aspirin, heparin, and other interventions in the prevention and treatment of fetal growth restriction. American journal of obstetrics and gynecology. 2018 Feb 1; 218(2): S829-S840.

11. Lydakis, C., Lip, G. Y., Beevers, M., Beevers, D. G. Atenolol and fetal growth in pregnancies complicated by hypertension. American Journal of Hypertension. 1999 Jun 1; 12(6): 541547.

12. Kleemann, D. O., Walker, S. K., Seamark, R. F. Enhanced fetal growth in sheep administered progesterone during the first three days of pregnancy. Reproduction. 1994 Nov 1; 102(2): 411-417.

13. Anthony, R. V., Pratt, S. L., Liang, R., Holland, M. D. Placental-fetal hormonal interactions: impact on fetal growth. Journal of Animal Science. 1995 Jun 1; 73(6): 1861-1871
14. Walsh, J. M., McGowan, C. A., Kilbane, M., McKenna, M. J., McAuliffe, F. M. The relationship between maternal and fetal vitamin D, insulin resistance, and fetal growth. Reproductive Sciences. 2013 May; 20(5): 536-541.

15. Jones, G., Strugnell, S. A., DeLuca, H. F. Current understanding of the molecular actions of vitamin $\mathrm{D}$. Physiological reviews. 1998 Oct 1.

16. Nagpal, S., Na, S., Rathnachalam, R. Non-calcemic actions of vitamin D receptor ligands. Endocrine reviews. 2005 Aug 1; 26(5): 662-687.

17. Brooke, O. G., Brown, I. R., Bone, C. D., Carter, N. D., Cleeve, H. J., Maxwell, J. D., et al., Vitamin D supplements in pregnant Asian women: effects on calcium status and fetal growth. Br Med J. 1980 Mar 15;280(6216):751-754.

18. Dror, D. K. Vitamin D status during pregnancy: maternal, fetal, and postnatal outcomes. Current Opinion in Obstetrics and Gynecology. 2011 Dec 1;23(6): 422-426.

19. Holick, M. F., Binkley, N. C., Bischoff-Ferrari, H. A., Gordon, C. M., Hanley, D. A., Heaney, R. P., et al., Evaluation, treatment, and prevention of vitamin D deficiency: an Endocrine Society clinical practice guideline. The Journal of clinical endocrinology \& metabolism. 2011 Jul 1; 96(7): 1911-1930.

20. Walker, V. P., Zhang, X., Rastegar, I. Cord blood vitamin D status impacts innate immune responses. Clin Endocrinol Metab. 2011; 96: 1835-1843.

21. World Health Organization. Vitamin D Supplementation in Infants. Geneva: World Health Organization. 2014.

22. De-Regil, L. M., Palacios, C., Ansary, A. Vitamin D supplementation for women during pregnancy. Cochrane Database Syst Rev. 2012; 2: CD00887.

23. Heaney, R. P. Is vitamin D inadequacy in early life an instance of the "Barker Hypothesis"? Nutr Today. 2016; 51: 14-17.

24. Zerofsky, M. S., Jacoby, B. N., Pedersen, T. L. Daily cholecalciferol supplementation during pregnancy alters markers of regulatory immunity, inflammation, and clinical outcomes in a randomized controlled trial. JNutr. 2016; 146: 2388-2397.

25. Wagner, C. L., McNeil, R. B., Johnson, D. D., Health characteristics and outcomes of two randomized vitamin D supplementation trials during pregnancy: a combined analysis. J Steroid Biochem Mol Biol. 2013; 136: 313-320.

26. Hollis, B. Circulating 25-hydroxyvitamin D levels indicative of vitamin D sufficiency: implications for establishing a new effective dietary intake recommendation for vitamin D. J Nutr. 2005; 135: 317-322.

27. Vieth, R., Bischoff-Ferrari, H., Boucher. The urgent need to recommend an intake of vitamin $\mathrm{D}$ that is effective. Am J Clin Nutr 2007; 85: 649-650. 